\title{
POR QUE OS ENFERMEIROS DEIXAM O EMPREGO: ESTUDO NUM HOSPITAL-ESCOLA *
}

\author{
Maria Luiza Anselmi**
}

ANSELMI, M.L. Por que os enfermeiros deixam o emprego: estudo num hospitalescola. Rev. Esc. Enf. USP, São Paulo, 24(2):237-250, ago. 1990.

$O$ presente trabalho, de carater retrospectivo, identifica $e$ analisa os motivos pelos quais os enfermeiros desligaram-se de seu emprego em um Hospital-Escola. $O$ periodo do estudo compreende 7 anos, entre 1979 e 1985.

UNITERMOS: Administração de serviços de enfermagem. Recursos humanos em enfermagem.

\section{INTRODUÇÃO}

Ao final da década de 50 , e no decorrer das décadas de 60 e 70 , surgem nos E.U.A., publicações sobre a rotatividade no trabalho hospitalar, especificamente de enfermeilos. Esses estudos evidenciam as proporções epidêmicas que esse fenômeno adquiria naquele país.

BRIEF (1986), revendo as causas do desligamento entre enfermeiros, classifica-as em dois tipos: as econômicas e as sociais; estas são decorrentes das responsabilidades familiares, especialmente o cuidado aos filhos que as mulheres devem assumir, já que a profissão é ainda predominantemente feminina; naquelas a questão salarial é preponderante.

Ao entrevistarem 111 enfermeiros desligados de seus empregos, PRESCOTT \& BOWEN (1987) procuram verificar se o hospital onde tinham trabalhado poderia ter feito alguma coisa para induzi-los a permanecer; $50 \%$ desses enfermeiros responderam afirmativamente e indicaram algumas estratégias nesse sentido como: programações e horários mais flexíveis de trabalho; melhoria na comunicação entre equipe e chefia; aumento salarial; melhores oportunidades de promoção; facilidade e agilidade no processo de transferência entre uma unidade e outra, dentro do próprio hospital; oportunidade para participar de programas de educação continuada.

BEINSON (1986), utilizando entrevistas de demissão e questionários, pesquisou as causas de desligamento de 125 enfermeiros. Os motivos apontados, em ordem decrescente, foram: pressões e stress no trabalho;

- Extrafdo da dissertação de mestrado apresentada em 1988 na Escola de Enfermagem do Ribelråo Preto - USP.

* Enfermeira. Assistente na Escola de Enfermagem de Ribeirão Preto - USP. 
salários e sistema de benefícios inadequados, baixa qualidade e conflitos na supervisão; conflito com a administração do hospital, médicos e outras categorias de pessoal; falta de oportuniảade para progredir; falta de incentivos e reconhecimento por um bom trabalho; trabalho cansativo/ tedioso; poucas oportunidades para realização profissional; problemas pessoais/familiares e domésticos.

Estudos dessa natureza são escassos na literatura nacional de enfermagem, entre eles pode-se citar o de BAPTISTA (1979) e o de BURLAMAQUE (1981).

Outro trabalho sobre o assunto foi realizado num Hospital-Escola por COSTENARO et alii (1987), onde os principais motivos de saída da instituição apontados pelo pessoal de enfermagem (enfermeiros, auxiliares e atendentes de enfermagem) foram: os financeiros (34\%); a vida social restrita devido à jornada de trabalho $(30 \%)$ e rodizio de horários $(15 \%)$.

Na vivência de uma prática administrativa em um hospital de ensino, observou-se que os enfermeiros admitidos na Instituição permaneciam por pouco tempo trabalhando, desligando-se em curto periodo. As demissões e as reposições ocorriam numa freqüência acentuada, às vezes, assustadora. As queixas das chefias dos serviços eram inúmeras, perante os constantes desequilibrios no quadro de enfermeiros, provocando sobrecarga de trabalho àqueles que continuavam, gerando dificuldades no atendimento às atividades demandadas na assistência ao paciente e, como conseqüência final, um comprometimento na quantidade e qualidade dos serviços prestados.

Para enfermeiros responsáveis pelos Serviços de Enfermagem, o conhecimento e análise das causas de demissão dos seus trabalhadores contribuirá para subsidiar a avaliação do trabalho de enfermagem, e neste sentido, possibilitará repensar as políticas de recursos humanos vigentes na instituição.

A inquietação acerca desta temática motivou o desenvolvimento do) presente estudo, onde procurou-se evidenciar e analisar as causas de desligamento dos enfermeiros de uma instituição hospitalar de ensino.

\section{METODOLOGLA}

Trata-se de um estudo exploratório, de caráter retrospectivo, desenvolvido num Hospital-Escola, o Hospital das Clínicas da Faculdade de Medicina de Ribeirão Preto da Universidade de São Paulo (HCFMRPUSP), localizado no interior do Estado de São Paulo, e que em março de 1988 contava com 555 leitos ativados, distribuidos da seguinte forma: 472 em sua sede - Campus Universitário e 83 na Unidade de Emergência, centro da cidade. $O$ quadro de pessoal era de 3850 servidores.

A Enfermagem, dentro da estrutura formal do hospital, constituise uma Divisão, mantendo subordinação direta à Superintendência. Na 
sua estrutura há 15 serviços de enfermagem, abrangendo todas as especialidades. O pessoal de enfermagem, em março de 1988 era de 1468 funcionários.

Delimitou-se para realização do estudo o periodo compreendido entre os anos de 1979 a 1985 (sete anos). Para identificação e caracterização das causas de desligamento utilizou-se o formulário "ficha de entrevista de demissão", (Anexo 1), instrumento já adotado pela própria Instituição, cujo preenchimento é feito pelo próprio demitente, no momento em que ele entrega sua solicitação de desligamento.

Embora, no periodo analisado, tenham ocorrido 171 desligamento de enfermeiros, apenas $138(80,7 \%)$ deles foram inseridos nas análises, correspondendo à quantidade de formulários preenchidos encontrados no Centro de Recursos Humanos do Hospital, na ocasião da coleta dos dados. Os demais, supóe-se que, decorrido tanto tempo, sete anos, até o momento deste trabalho, tenham se extraviado devido a inexistência de um sistema acurado de controle, garantindo que todos os enfermeiros demitentes preenchessem a ficha de entrevista.

Pelo instrumento utilizado obteve-se o perfil do enfermeiro demitente quanto a idade, estado civil, unidade de lotação e tempo de permanência no serviço antes do desligamento. $E$ ainda, informações sobre as razões do desligamento, as impressōes a respeito da Instituição, condições de trabalho, supervisão e relacionamento com a chefia.

\section{RESULTADOS E DISCUSSÃO}

\section{Caracterização do enfermeiro demitente}

Os demitentes foram agrupados conforme o local onde desempenhavam suas atividades, por ocasião do desligamento. Como os Serviços de Enfermagem reunem várias seções de especialidades diferentes, procurou-se uma designação que melhor situasse a área de trabalho do enfermeiro. (Tabela 1)

E no Serviço de Enfermagem Médica e Cirúrgica da Unidade de Emergência (UE), onde aconteceram o maior número de desligamentos no período. A demanda de pacientes pela UE é intensa por tratar-se de um Pronto Socorro que atende a região. A complexidade de cuidados decorrentes da gravidade das condiçōes dos pacientes submete o pessoal de enfermagem a um stress contínuo e a uma sobrecarga de trabalho, refletida na elevada taxa de ocupação dos leitos. Nos anos de 1983, 1984 e 1985, excluindo-se os leitos de pediatria, os de adulto apresentaram uma percentagem de ocupação, em média para os 3 anos, de $114,0 \%$. Em 1987, os leitos de adultos tiveram uma taxa de ocupação de 154,5\%, revelando ser praticamente impossivel atender uma demanda $54 \%$, acima das previsões, sem que haja um desgaste de sua força de trabalho.

O stress de enfermeiros no trabalho é denominado na literatura americana "burnout" e vários estudos a respeito tem sido desenvolvidos. Veninga; Pirves \& Malach citados por HARRIS (1984), definem "bur- 
DISTRIBUIÇAO DOS ENFERMEIROS DEMITENTES ENTREVISTADOS DO HCFMRP-USP, NO PERTODO DE 1979 A 1985, SEGUNDO AREA DE TRABALHO

\begin{tabular}{|c|c|c|}
\hline Area de Trabalho & $\begin{array}{l}\text { Número } \\
\left(\mathbf{N}^{\circ}\right)\end{array}$ & $\begin{array}{l}\text { Porcentagem } \\
(\%)\end{array}$ \\
\hline Serv. Enf. Médica e Cirúrgica * & 24 & 17,39 \\
\hline Serv. Finf. Pediatria & 17 & 12,32 \\
\hline $\begin{array}{l}\text { Serv. Enf. - Psiquiatria, Neurologia, Dermatologia e } \\
\text { Hospital-Dia }\end{array}$ & 12 & 8,69 \\
\hline Serv. Enf. Médica & 12 & 8,69 \\
\hline Serv. Enf. Cirúrgica & 11 & 7,92 \\
\hline $\begin{array}{l}\text { Serv. Enf. Recuperação Anestésica - Apoio Anestésico e } \\
\text { Salas de Operação }\end{array}$ & 11 & 7,97 \\
\hline $\begin{array}{l}\text { Serv. Enf. Centro de Terapia Intensiva - Unidade } \\
\text { Transplante Renal }\end{array}$ & 11 & 7,97 \\
\hline Serv. Fnf. Pediatria * & 10 & 7,25 \\
\hline Serv. Enf. Recuperação e Central de Material * & 9 & 6,52 \\
\hline Serv. Enf. Ortopedia, Oftalmologia e Otorrinolaringologia & 9 & 6,52 \\
\hline Serv. Enf. Ginecologia e Obstetrícia & 5 & 3,62 \\
\hline Serv. Enf. Central Material & 2 & 1,45 \\
\hline Serv. Enf. Saúde Pública & 2 & 1,45 \\
\hline Serv. Enf. Ambulatório & 2 & 1,45 \\
\hline Comissão Infecção & 1 & 0,72 \\
\hline Total & 138 & 100 \\
\hline
\end{tabular}

(*) - Serviços localizados na Unidade de Emergência.

nout" como um 'conjunto de sinais e sintomas, de cansaço ou esgotamento físico e mental, acarretado por condições de trabalho frustrantes que levam a uma diminuição da produção e a insatisfação'. Esses mesmos autores relacionam o absenteismo e altas taxas de rotatividade no trabalho ao "burnout", salientando que as respostas comuns a essa sindrome é o indivíauo deixar a profissão, abandonar e/ou mudar de emprego.

Pode-se pensar que os enfermeiros desse serviço estejam sofrendo um processo de stress, desgaste e sobrecarga de trabalho, semelhante ao descrito acima, e neste sentido caberia estudos mois detalhados, escassos na literatura brasileira até o momento.

Detectou-se, durante a pesquisa, a predominância de mulheres no grupo estudado $(97,83 \%)$. Os solteiros também respondem por um per- 
centual elevado, em torno de $51 \%$ e os casados por $45,6 \%$. Os demitentes com idade variando entre 22 e 26 anos compöem $59 \%$ do total de solteiros. Portanto, o pessoal jovem, sem os compromissos do casamento e familiares, desligam-se em maior número, talvez em busca de novas oportunidades de trabalho.

Quanto ao tempo em que esses enfermeiros trabalharam no Hospital, nota-se que $26,80 \%$ deles tinham menos de um ano de serviço, assim como $28,98 \%$ possuiam mais de 4 anos. Deste último grupo, excluindo-se três enfermeiros $(2,17 \%)$ que se aposentaram com tempo de serviço no HC, tem-se $26,80 \%$. Ĺogo, a Instituição perdeu, no periodo de estudo, tanto enfermeiros com pouco tempo de serviço, em fase de adaptação, como enfermeiros mais experientes, em proporções iguais. Outro fato importante é que $44,21 \%$ dos demitentes tinham entre 9 meses e menos de 4 anos, tempo suficiente para aquisição de habilidades e experiências e enfrentar novos mercados de trabalho. (Tabela 2)

TAB ELA 2

DISTRIBUIÇAO DOS ENFERMEIROS DEMTTENTES EINTREVISTADOS DO HCFMMRP-USP, NO PERIODO DE 1979 A 1985, DE ACORDO COM O TEMMPO DE SEIRVIÇO PRESTADO

\begin{tabular}{|c|c|c|}
\hline Tempo de Servigo & $\begin{array}{c}\text { Numero } \\
\left(\mathbf{N}^{\varphi}\right)\end{array}$ & $\begin{array}{c}\text { Porcentagem } \\
(\%)\end{array}$ \\
\hline $0 \mid-3 \mathrm{~m}$ & 9 & 6,52 \\
\hline $31-6 \mathrm{~m}$ & 14 & 10,14 \\
\hline $61-9 \mathrm{~m}$ & 7 & 5,07 \\
\hline $9 \longmapsto 12 \mathrm{~m}$ & 7 & 5,07 \\
\hline $1 a-2 a$ & 19 & 13,77 \\
\hline $2 a 1-3 a$ & 21 & 15,22 \\
\hline $4 a-5 a$ & 14 & 10,14 \\
\hline $5 a 1-6 a$ & 10 & 7,25 \\
\hline $6 a 1-7 a$ & 7 & 5,07 \\
\hline 7 anos ou mais* & 9 & 6,52 \\
\hline Total & 138 & 100 \\
\hline
\end{tabular}

- Incluem-se no intervalo 3 enfermeiros que aposentaram por tempo de servico (20 a 25 anos).

A mediana de tempo de serviço, para esse grupo de enfermeiros, foi de 2 anos e 7 meses. Acredita-se que, baseados no fato de grande parte dos demitentes terem de 22 a 26 anos, estes sejam recém-formados, e observando-se a permanência média de 2 anos e 7 meses, poder-se-ia 
pensar que o hospital esteja se constituindo efetivamente em campo de treinamento, onde o enfermeiro dá continuidade ao seu aprendizado, consolida habilidades para, com maior segurança, enfrentar o mercado de trabalho.

\section{As razões do desligamento}

Ao responderem sobre as razões pelas quais se desligaram, os enfermeiros expuseram vários motivos omitindo porém, a ordem de prioridade entre eles, produzindo assim, respostas múltiplas. A mudança de cidade e o trabalho em outra empresa somam percentuais elevados (58\%). Problemas relacionados à família também são razões apontadas em grande freqüência. Enquanto COSTENARO et alii (1987), em 1984 aludiram a política salarial do hospital como responsável por $34 \%$ dos desligamentos do pessoal de enfermagem, neste estudo ,o baixo salário não se destaca como um motivo preponderante no desligamento. (Tabela 3)

\section{TABELA 3}

FREQUENCIA DAS RAZOES DE DEMISSIAO FMITIDAS NAS RESPOSTAS

MOLTIPLAS DE ENFERRMEIROS DEMITENTES ENTREVISTADOS DO HCFMRP-USP, NO PERIODO DE 1979 A 1985

\begin{tabular}{lrc}
\hline Razóes & $\begin{array}{c}\text { Número } \\
(\mathbf{N})\end{array}$ & $\begin{array}{c}\text { Porcentagem } \\
(\%)\end{array}$ \\
\hline Mudança de cidade & 55 & 29,89 \\
Recrutado por outra empresa & 51 & 27,72 \\
Família & 30 & 16,30 \\
Baixo salário & 14 & 7,61 \\
Nova profissão & 9 & 4,89 \\
Estudos & 5 & 2,72 \\
Inadaptação ao Hospital & 4 & 2,17 \\
Relacionamento & 4 & 2,17 \\
Não prorrogação do contrato & - & - \\
Outras razóes* & 12 & 6,52 \\
\hline Tot a l & 184 & 100 \\
\hline
\end{tabular}

(*) Onze enfermeiros indicaram aqui o casamento como razăo de demissáo.

Os comentários dos enfermeiros sobre o motivo da demissão, auxiliam na análise e detalham as informações da tabela anterior. Três grandes grupos configuram os motivos de desligamento: mudança de emprego, insatisfação com a sistemática de trabalho proposta pela Divisão de Enfermagem e problemas familiares. Os enfermeiros têm buscado outro 
emprego que lhes propicie oportunidades profissionais mais amplas, incluindo a chance de poderem estudar e se desenvolverem dentro da profissão, conduzindo-os inclusive a ascensão na carreira, a postos de direção. (Tabela 4)

\author{
TABELA 4
}

FREQUENCIA DOS COMENTARIOS SOBRE O MOTTVO DA DEMISSAO PELOS EINFERRMEIROS DEIMITENTES DO HCFMRP-USP, NO PERTODO DE 1979 A 1985 (RESPOSTAS MOLTIPLAS)

\begin{tabular}{|c|c|c|}
\hline Comentários & $\begin{array}{l}\text { Numero } \\
(\mathbf{N})^{\prime}\end{array}$ & $\begin{array}{l}\text { Poncentagem } \\
(\%)\end{array}$ \\
\hline $\begin{array}{l}\text { MUDANCA DE FIMPREGO } \\
\text { - melhores perspectivas profissionais } \\
\text { - exercer atividades na área de Saude Pública } \\
\text { - melhor horário de trabalho } \\
\text { - trabalhar na Universidade como docente em unidades do } \\
\text { Enfermagem } \\
\text { - melhor salário } \\
\text { - estar proximo a familia } \\
\text { - trabalhar em outro hospital } \\
\text { - trabalhar como enfermeira na aeronáutica } \\
\text { - outra profissåo }\end{array}$ & $\begin{array}{r}89 \\
16 \\
14 \\
13 \\
12 \\
11 \\
11 \\
5 \\
4 \\
3\end{array}$ & $\begin{array}{r}54,95 \\
9,88 \\
8,64 \\
8,02 \\
\\
7,42 \\
6,79 \\
6,79 \\
3,09 \\
2,47 \\
1,85\end{array}$ \\
\hline $\begin{array}{c}\text { INSATISFAÇA COM A SISTEMATICA DE TRABALHO } \\
\text { PROPOSTA PEMA DIVISAO DE ENFERMAGEMM }\end{array}$ & 6 & 3,70 \\
\hline $\begin{array}{l}\text { PROBLFMLAS FAMTLIARES } \\
\text { - mudança de cidade acompanhando marido } \\
\text { - dedicar-se ao cuidado dos filhas } \\
\text { - casamento e consequiente mudança de cidade } \\
\text { - nåo especificados }\end{array}$ & $\begin{array}{r}52 \\
18 \\
13 \\
12 \\
9\end{array}$ & $\begin{array}{r}32,09 \\
11,11 \\
8,02 \\
7,40 \\
5,56\end{array}$ \\
\hline MOTTVOS PARTICULARES & 6 & $\mathbf{3 , 7 0}$ \\
\hline SEM COMENTARIOS & 9 & 5,56 \\
\hline Total & 162 & 100 \\
\hline
\end{tabular}

Condições de trabalho relativas ao horário e salários também foram comentados, entretanto, o salário freqüentemente apontado pelo senso comum, como um forte motivo de desligamento, aparece explicitamente em $5^{\circ}$ lugar dentre outras causas. $\mathrm{E}$ importante lembrar que, no periodo estudado, a área hospitalar pública remunerava melhor seus profissionais que a área privada CONSELHO FEDERAL DE ENFERMAGEM (1985). Ademais há possibilidade de questão dos salários estar embutida em outros motivos, indicados pelos enfermeiros sobretudo, nos motivos "recrutado por outra empresa" e "nova profissão".

Seja na dedicação ao cuidado de filhos pequenos ou no acompanhamento ao marido que muda de emprego para outra cidade, e, ainda, pelo casamento que exige também uma mudança de cidade, os problemas relativos à familia reuniu $32 \%$ dos motivos de saída. Considerando a pre- 
dominância de enfermeiras, estes motivos estão associados à problemática do trabalho feminino. $\AA$ A medida em que a mulher não sustenta maís a dupla jornada - hospital e lar, ela assume todos os encargos e aceita ter sua carreira prejudicada (BRUSCHINI \& ROSEIMBERG, 1982).

Para SILVA (1979), as enfermeiras encontram dificuldades em conciliar seus papéis profissionais e domésticos, porque estão sujeitas a horários rigidos de trabalho, sobretudo a plantões periódicos. Neste caso, as relações conjugais podem ser afetadas, existindo um rodizio acentuado de horários de plantões, com noturnos e diurnos, dificultando ao profissional organizar sua vida familiar.

\section{As condições de trabalho e supervisão}

A maioria dos enfermeiros apreciava o trabalho realizado, tinham conhecimento das ativiclades, de suas responsabilidades e as desempenhavam com segurança. Quanto à orientação dada pela chefia $24 \%$ consideram-na regular e insatisfatória. Em relação a distribuição do trabalho, entre os membros da equipe, pela chefia, apenas $11 \%$ apontaram parcialidade.

Para $73 \%$ dos enfermeiros demitentes, o relacionamento da chefia para com os servidores é satisfatório, porém, 26,09\% o consideraram regular e insatisfatório.

As questões abordadas nos itens 4 e 5 do instrumento parecem não refletir a verdadeira opinião dos enfermeiros, sendo discutíveis os resultados obtidos. Primeiramente, pela forma como estão claboradas; segundo, alguns entrevistados, receosos em se manifestarem tão abertamente, caso pensem em retornar futuramente ao trabalho no $\mathrm{HC}$, omitem suas reais opiniōes.

\section{Apreciaçōes sobre o trabolho na Instituição}

Os enfermeiros caracterizaram o relacionamento existente entre equipe, pacientes, chefia e colegas, um dos fatores que mais os agradava no hospital, assim como o próprio trabalho que realizavam. Parece que todos os três fatores estejam instrinsicamente relacionados. (Tabela 5)

Ressaltaram a possibilidade que a instituição oferece para prestarem a assistência direta ao paciente $(15,11 \%)$. Contudo, é impossivel conhecer, neste estudo, a ỉimensão e a frequiência em que eles realizam esta assistência. TREVIZAN (1986), em estudo recente, afirma que, apesar de "apregoado teoricamente que o enfermeiro deve dedicar-se à assistência direta aos pacientes e fazer dele seu objeto de trabalho", neste hospital encontrou que o "enfermeiro não chega a dedicar um quinto do seu tempo a essas funções". A análise de seus resultados revelou "que a porcentagem de tempo dedicado a funções de assistência direta ao paciente é pequena, se comparada ao total das outras funções em conjunto".

O HCFMRP-USP, para os enfermeiros demitentes, enquanto mercado de trabalho propicia oportunidade de desenvolvimento profissional, aquisição de conhecimentos, por tratar-se de uma instituição cujas metas envolvem o ensino, a pesquisa e a assistência. 
FREQUENCIA DAS OPINIOES EMITIDAS PELOS ENFERMEIROS DEMITENTES ENTREVISTADOS NO HCFMRP-USP, SOBRE O QUE MAIS AGRADAVA NA INSTTTUIÇAO, NO PERIODO DE 1979 a 1985 (RESPOSTAS MULTIPLAS)

Opiniีo

Numero Porcentagem

$\left(\mathbf{N}^{\circ}\right)$

(\%)

Bom relacionamento mantido com: pacientes, colegas, servidores, médicos e chefia

O trabalho que realizava e o ambiente em que ele se desenvolvia

Possibilidade de realizar o cuidado direto ao paciente

A organização da Instituição, com distribuição de funçes

A oportunidade de adquirir novos conhecimentos, experiência, aprimorando a formação e a consciência profissional

Boas condições materiais - equipamentos, aparelhos e financeiras para se realizar o trabalho

Bom atendimento dispensado aos pacientes

$\begin{array}{rr}10 & 7,19 \\ 6 & 4,32 \\ 5 & 3,60 \\ 4 & 2,88 \\ 8 & 5,75 \\ 3 & 2,16\end{array}$

Segurança e estabilidade no emprego 3,60

Orientação e apoio recebido da chefia imediata 2,88

Outros

Identificaram também que o hospital reúne condições materiais, financeiras e de estrutura organizacional primordiais a prestação de uma assistência médica e de enfermagem qualificadas.

Os horários de trabalho e as alterações freqüentes de turnos são aspectos relatados como de desagrado, ocupando percentual de destaque. Assim como em outros hospitais, SCHMUDT (1984) salienta que "a elevada tensão emocional, associada a longas jormadas de trabalho, condições de insalubridade do ambiente de trabalho, baixa remuneração e o duplo emprego acarretam absenteismo em larga escala. Este por sua vez, aumenta a carga de trabalho da equipe, pois as necessidades do paciente indeperdem do contingente de pessoal em serviço". Lembra ainda que esse pessoal geralmente está sujeito a trabalhar em condições penosas e desagradáveis, pela necessidade de rodízio de escalas de plantões, diurnos e noturnos, inclusive sábados, domingos e feriados. (Tabela 6)

A burocracia excessiva também é uma condição desagradável $(16,67 \%)$, levantada pelos demitentes. A esse respeito, estudo aprofundado foi desenvolvido por TREVIZAN (1986). Para ele "os enfermeiros 
TAB ELA 6

FREQUENCIA DAS OPINIOES EMITIDAS PEILOS ENFERMEIROS DEMITEINTES DO HCFMRP-USP, SOBRE O QUE MAIS DESAGRADAVA NA INSTTTUIÇAO, NO PERIODO DE 1979 A 1985 (RESPOSTAS MULTIPLAS)

Opiniåo Número Porcentagem

(N?)

(\%)

As escalas de trabalho com rodizio de horários 42 26,92

Burocracia excessiva 26 16,67

A estrutura da Divisåo de Enfermagem: supervisão, avaliação, comunicaçåo

$\begin{array}{rr}18 & 11,64 \\ 15 & 9,62 \\ 8 & 5,13 \\ 5 & 3,20 \\ 4 & 2,56 \\ 3 & 1,92 \\ 6 & 3,85 \\ 29 & 18,59\end{array}$

Relacionamento entre funcionários enfermeiros

Insuficiencia de funcionários para realizar o trabalho

Pouca valorizaçăo do profissional enfermeiro e a funcão restrita que lhe $e$ atribuida

pensam que a burocracia é sinônimo de preenchimento de papéis, de fichas de seguimento rígido de quesitos estatutários ou regimentais", “... talvez falte às enfermeiras o entendimento de que o mal da burocracia não está, necessariamente, no cumprimento de rotinas e normas, mas em ser apenas isto, ou em restringir-se a isto, de forma marcante e impessoal". O apego exagerado às normas e rotinas, para atender solicitações da própria instituição, possivelmente, tenha bloqueado ou cerceado o potencial de criatividade do enfermeiro, expresso aqui na terminologia "burocracia excessiva".

Reunindo os percentuais de respostas nos tópicos 1,2 e 4 da Tabela $6(53,21 \%)$, é possivel afirmar que existem fortes indícios de insatisfação dos enfermeiros concernentes a instituição. Chama atenção a incoerência entre esses resultados com aqueles obtidos nos itens 4 e 5 do instrumento, onde um percentual elevado de enfermeiros gostavam do trabalho que desenvolviam e aprovavam o relacionamento entre chefia e subordinados.

Dos respondentes, $11,54 \%$ levantaram questões em relação à administração realizada pela Divisão de Enfermagem, abordando tópicos como supervisão, avaliação do trabalho, a comunicação exercida entre a base e a cúpula administrativa. 
No último ítem àa enirevista, observaçồes sobre a instituiçằo, $60 \%$ dos demitentes omitiram suas observações, o que prejudicou, sensivelmente, a análise.

As sugestões referem-se a condições de trabalho - horários mais fixos e flexibilidade nas escalas mensais, com facilidades de mudanças para atender, não só necessidades de serviço, mas também do servidor; melhoria nos relacionamentos interpessoais. No entender dos demitentes, estas sugestões, se implementadas, viriam contemplar a continuidade do trabalho, portanto, da assistência de enfermagem. Concomitantemente permitiria ao servidor planejar e organizar sua vida pessoal. (Tabela 7)

\section{TABELA 7}

FREQUANCIA DAS OBSERVAGOES SOBRE A INSTTTUIÇAO EMTITDAS PELOS ENFERMEUTOS DEIMITENTES ENTREVISTADOS, DO HCFMRP-USP, NO PERIODO DE 1979 A 1985 (RESPOSTAS MULTIPLAS)

Obaervagies

Procurar estabelecer horários de trabalho mais fixos

Melhorar relacionamento e entrosamento entre as pessoas dentro da Instituiça
Numero Porcentagem

(Nי)

$(\%)$

Maior flexibilidade nas escalas de trabalho, possibilitando alteraç̋es quando fossem necessárias ao servidor

Melhorar orientaçă, supervisăo e avaliação do trabalho

Suprir deficiencia de recursos humanos com a contrataça de novos servidores

Propiciar facllidades a condiçes ao enfermeiro e outros servidores para estudarem.

Diminuir a burocracia

Revisto das fungores desempenhadas pelo enfermeiro

Outros

Sem observacoes
11

10

17,75

7,04

7,75

4,22

6

4,22

$$
6
$$

6

4

4

2,82

3

2,11

7

4,93

85
59,86

As dificuldades de relacionamento, resultantes talvez da macroestrutura da instituição são questões a serem revistas. A orientação, supervisão e avaliação do trabalho mereceriam análises mais acuradas por parte da diretoria da Divisão de Enfermagem, e parece já ser esta uma preocupação deste órgão, que através da Comissão de Educação Continuada em Enfermagem, tem procurado envolver e conduzir os en- 
fermeiros a uma reflexẫo mais profunda e crítica a respeito de suas verdadeiras funções e papéis no trabalho hospitalar.

\section{CONCLUSOES}

Conquanto tenham existido limitações na análise das causas de desligamento dos enfermeiros, algumas conclusões são válidas para o grupo de 138 demitentes efetivamente entrevistados, a saber:

- do grupo de enfermeiros demitentes estudados, cerca de $30 \%$ trabalhavam em serviços com elevado percentual de ocupação dos leitos, acima de $100 \%$, o que traduz prováveis sobrecargas de trabalho e niveis altos de stress.

- 51\% eram enfermeiros solteiros e deste grupo, 59\% tinham idade variando entre 22 e 26 anos, logo, pessoas jovens, das quais se espera trabalho efetiva na profissão.

- A mediana de tempo de serviço no hospital foi de 2 anos e 7 meses.

- As causas mais apontadas para o desligamento foram: mudança de cidade $(29,89 \%)$; recrutamento por outra empresa $(27,72 \%)$; a família $(16,30 \%)$ e o salário $(7,61 \%)$.

- Ao comentarem as razões da demissão, os enfermeiros referiram que ele ocorreu devido a mudança de emprego, buscando melhores perspectivas profissionais. A Universidade - Escolas de Enfermagem e a área de Saúde Pública foram setores que mais absorveram os enfermeiros demitentes do HCFMRP-USP. O outro emprego também oferecia ao enfermeiro melhores horários de trabalho e salários. As questões familiares totalizaram $(32,09 \%)$ dos comentários a respeito do desligamento.

- Embora os enfermeiros tenham afirmado que gostavam do trabalho, consideravam o relacionamento chefia-subordinado e a distribuição do trabalho, satisfatório; quando opinam sobre os aspectos que mais desagradavam, manifestaram sua insatisfação referente às condições de trabalho, relacionamento e ainda, a supervisão, avaliação e comunicação vigente na Divisão de Enfermagem.

- No momento de apresentarem sugestões, há uma ênfase acerca das condições de trabalho, especialmente, flexibilidade nas escalas e horários mais fixos. A burocracia institucional os enfermeiros atribuiram a responsabilidade pelo desvio de suas reais funções, seja da assistência direta ou da supervisão, coordenação e orientação a equipe.

Emergem timidamente, as reivindicações no sentido de obterem condições e espaços, a nivel institucional, para participação em programas de educação continuada.

A partir das análises realizadas acredita-se poderão emergir formas alternativas que promovam transformações $e$, consequientemente propi- 

trabalho em enfermagem no âmbito hospitalar.

ANSELMI, M.L. Why nurses leaves the job: study in an University Hospital. Rev. Esc. Enf. USP, São Paulo, 24(2):237-250, Aug. 1990.

The present retrospective study identifies and analyses the reasons for nurses resignation of the job in an University Hospital from 1979 to 1985.

UNITERMS: Nursing services administration. Nursing manpower.

\section{REFERENCIAS BIBLIOGRAFICAS}

BAPTISTA, W.A. Contribulcão ao estudo da assistência de enfermagem: análise de alguns fatores relacionados a administraça em enfermagem que podem interferir na assistência ao paciente. Ribeirão Preto, 1979. (Dissertação de mestrado - Escola de Enfermagem de Ribeirão Preto da USP).

BENSON, G.L. The hidden costs in nursing turnover. J. Nurs. Adm., Wakefleld, 16(5):5-17, May 1986.

BRIEF, A.P. Turnover among hospital nurses: a suggested model. J. Nurs. Adm., Wakefleld, 6(8):55-8, Oct. 1986.

BRUSCHINI, M.C. \& ROSFMBERG, F. Trabalhadores do Brasll. Săo Paulo, Brasillense, 1982.

BURLAMAQUE, C.S. Fstudo do desempenho do enfermeiro de um hospital em nivel de unidade de internaçăo. Porto Alegre, 1981. (Dlssertacăo de mestrado - Hocola de Enfermagem da UFRGS).

CONSELHO FEDERAL DE FNFGRMAGEM. O exercicio da enfermaxem nas instituicoes de saúde do Brasil 1982/1983: forca do trabalho em enfermagem. Rlo de Janeiro, Associaço Brasileira de Enfermagem, 1985. $\nabla .1$.

COSTENARO, O.M.V. et alil. Rotatividade de pessoal: causas, consequênclas e propostas. Rev. Paul. Finf., Săo Paulo, 7(1):40-3, jul./dez. 1987.

HARRIS, P.L. Burnot in nursing administration. Nurs. Adm. Q., Germantown, 8(3):61-70, Spring 1984.

PRESCOTT, P.A. \& BOWEN, S.A. Controlling nursing turnover. Nurs, Manak., Chicago, $18(6): 60-6$, June 1987 .

SCHIMIDT, M.J. Natureza das condiçóes de trabalho de enfermagem. Rev. Paul. Inf., Bao Paulo, 4(3):89-94, Jul./set. 1984.

SILVA, G.B. Desenvolvimento da enfermagem: correlaçăo dos problemas da profisẵo e da mulher na socledade. In: CONGRESSO BRASILEIRO DE BNFFRMAGEM, 31., Fortaleza, 1979. Anais. Brasilia, Associação Brasileira de Enfermagem, 1979. p. 27-32.

TREVISAN, M.A. A funcho administrativa da enfermeira de instituicăo hospltalar burocratizada. Ribeirăo Preto, 1986. 200 p. (Tese de doutorado - Fracola de Enfermagem de Rlbeirăo Preto - USP). 


\section{A NEXO 1}

FICTHA DE ENTREVISYTA DE DEMISSIAO

1. Identificacaso do servidor

Nome.

Funçăo-atividade

Lotado.

Idade.

Estado Civn

Data da admissão

Data do pedido de demissão.

Nome do(a) Chefe imediato.

2. Razס̃es da Demissão:

( ) Baixo salário

( ) Estudos

( ) Recrutado por outra empresa

( ) Familia

( ) Nova profissåo

( ) Inadaptaçăo ao Hospital

( ) Relacionamento

( ) Não prorrogą̧̃o de contrato

( ) Mudança de Cidade

( )

3. Comentário do Entrevistado sobre o motivo da demissão

4. Condiças de trabalho:

Gostava do trabalho que realizava?

Conhecia suas responsabilldades $\theta$ tarefas?

Sentia seguranga no cargo?

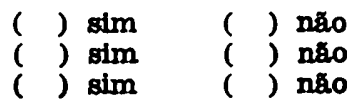

5. Condiçres de supervisăo:

Como é a orientagăa técnica da Chefia?

() satisfatória () regular ( ) insatisfatória

Como é a distribuiça de trabalhos pela Chefia

( ) igualdade ( ) parcialidade

Qual a sua opiniåo sobre o relacionamento da Chefia com os servidores?

$\begin{array}{lll}\text { ( ) satisfatório } & (\text { ) regular } & (\text { ) insatisfatório }\end{array}$

6. Opiniåo pessoal sobre o Hospital:

O que mais agradava?.

O que mais desagradava?

7. Deseja fazer alguma observaça?

DATA 